\title{
Adaptive DC-Link Voltage Control of LLC Resonant Converter
}

\author{
Li-Chung Shih, Yi-Hua Liu, and Yi-Feng Luo
}

\begin{abstract}
In this study, an adaptive DC-link voltage control of a two-stage switching power supply with LLC resonant converter is proposed. With this control method, the frequency variation range can be reduced and the conversion efficiency under different load conditions can be improved compared with the conventional variable frequency control technique. By operating the LLC resonant converter near its resonant frequency, circulating loss as well as the conduction loss can be reduced and optimal design of LLC resonant converter can be made possible. Moreover, no additional auxiliary circuits are required for the proposed method. The operational principle of the proposed control scheme is verified with a $350 \mathrm{~W}$ prototyping circuit. The switching-frequency-variation range is reduced from 12 to $4 \mathrm{kHz}$ and the efficiency is improved from $89.4 \%$ to $90.2 \%$ at full load.
\end{abstract}

Index Terms-Adaptive DC-link control, LLC resonant converter, two-stage switching power supply.

\section{INTRODUCTION}

$\mathrm{W}$ ITH the prevalence of the Internet and advancements in telecommunication technology, demand for power supply fields, such as server and telecom power supplies, has increased. Additionally, consumers have high requirements for power supply efficiency, volume, power density, and reliability [1]-[3]. Regarding the application of server and telecom power supplies, two-stage switching power supply (SPS) remains the mainstream architecture [4], [5]. In addition, two-stage SPS can also be employed in plug-in electrical vehicle (PEV) applications. Power factor correction (PFC) is usually the first stage of two-stage SPS, allowing the input current to become sinusoidal and in phase with the input voltage to increase the usage of mains electricity. The PFC stage usually utilizes a typical boost converter architecture that converts alternating current (AC) mains electricity to high-voltage direct current (DC). The second stage utilizes a DC-DC converter architecture to provide isolation as well as a stable output voltage. For two-stage SPS, digital signal controllers have increasingly been employed because of advancements in their functionalities. The block diagram for two-stage digital SPS is shown in Fig. 1.

Because most conventional DC-DC converters do not possess soft switching mechanisms [6], power supply efficiency is

Manuscript received July 30, 2018. This work was financially supported by the Taiwan Building Technology Center from The Featured Areas Research Center Program within the framework of the Higher Education Sprout Project by the Ministry of Education in Taiwan.

The authors are with the Department of Electrical Engineering, National Taiwan University of Science and Technology (e-mail: yhliu@mouse.ee.ntust. edu.tw; 110102204@mail.ntust.edu.tw; YF.Luo@mail.ntust.edu.tw).

Digital Object Identifier 10.24295/CPSSTPEA.2018.00018

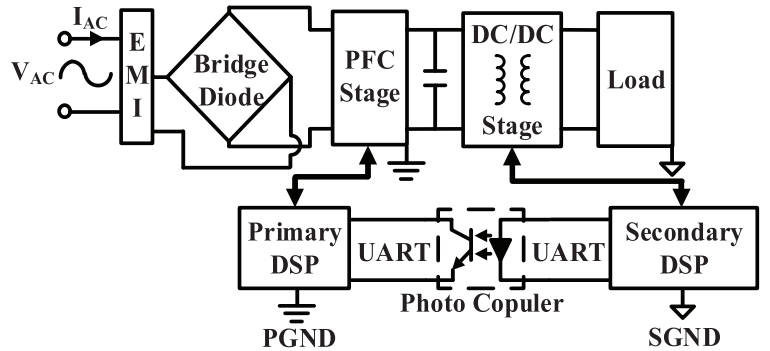

Fig. 1. Block diagram of a two-stage digital SPS.

difficult to improve. Hence, current DC-DC converters typically use the phase shift full bridge (PSFB) converter or LLC resonant converter, which has soft switching characteristics. PSFB converters can achieve zero voltage switching (ZVS) and are suitable for medium- and high-power applications; therefore, they are often used in the DC-DC converters of server, telecom or PEV power supply systems. Compared with conventional full bridge converters, PSFB converters have higher efficiency; however, PSFB converters exhibit problems such as difficulty in achieving ZVS at light load, duty cycle loss, circulating-current loss, and the parasitic ringing phenomenon [7]-[10].

Compared with PSFB converters, LLC resonant converters can not only achieve ZVS on the primary side but also attain zero current switching (ZCS) on the secondary side. In addition, problems related to the circulating current on the primary side of the LLC resonant converter are less severe. Thus, LLC resonant converters are more efficient than PSFB converters and have gradually become more prevalent for DC-DC converter applications. However, LLC resonant converters possess deficiencies. Generally, the optimal performance of an LLC resonant converter occurs when the switching frequency equals the resonant frequency [11]-[16]. However, this is difficult to achieve without adding mechanisms such as changes to the resonant tank parameters [12], [13] or modulation of the LLC resonant converter input voltage [14]-[16]. In addition, the LLC resonant converter relies on a frequency control mechanism to achieve voltage regulation. In conditions of improper design or applications where a wide input/output range is required [17][20], the switching frequency of LLC resonant converter may vary excessively, causing inefficiency and even leading to problems in designing magnetic components.

Numerous studies have adopted measures to enhance the overall efficiency of LLC resonant converters. A dual-transformer strategy was utilized in [19] to handle relatively wide input voltage ranges. Compared with the conventional LLC resonant converter, this design developed more operating modes, such as the increased flexibility to minimize the magnetizing 
current and reducing copper and iron loss from the transformer to enhance overall efficiency; however, the auxiliary circuit, winding of the dual transformers, and two rectification output stages complicate the circuit. An auxiliary LC circuit (containing an inductor and a capacitor) was used in [21], which functioned as a variable inductor, providing substantial magnetizing inductance at all times according to the switching frequency to reduce the circulating current of the LLC resonant converter, thereby improving the overall efficiency. Nonetheless, the transformer size becomes larger than that of a conventional LLC resonant converter if the LC auxiliary coil should be winded into the transformer. The research team in [22] modified the design of the transformer and the winding method to improve the overall efficiency of the LLC resonant converter; however, the improvement was limited. In [23], researchers suggested a dynamic adjustment of the dead time (DT) of LLC resonant converters to enhance overall efficiency; this means DT is short when the load is large, and vice versa. This method detected the center point voltage between the high side and low side MOSFET to determine the optimal timing for ZVS. However, this DT adjustment method is only suitable for region 1 operation of the LLC resonant converter, in which the frequency is higher than the resonant frequency. If employed in other regions of the LLC resonant converter, this method improves efficiency only to a limited extent. When operating in a region with a frequency lower than the resonant frequency, the resonant current value that enables the MOSFET to achieve ZVS is irrelevant to load level but is related to the value of the magnetizing inductance.

Studies have improved LLC resonant converter efficiency by adjusting LLC input voltage to keep the switching frequency close to the resonant frequency. This methodology comprises three methods: The first method controls LLC resonant converter in an open loop manner [14]-[16]; this method adjusts the input voltage by detecting variations of the output voltage, ensuring that the input-to-output voltage gain of LLC resonant converter stays at 1, as shown in Fig. 2.

The first method is often employed in systems with a variable output voltage, such as battery charging, where an LLC resonant converter only has to provide system isolation and high-efficiency voltage conversion. Additionally, this type of system does not need to consider the transient response.

The second method lets the switching frequency track the resonant frequency [3]. When the switching frequency of the LLC resonant converter deviates from the resonant frequency, step-size adjustment is used to adjust the input voltage step by step. This process continues until the switching frequency falls into the setting frequency range, as shown in Fig. 3. However, the step-by-step adjustment of the PFC's input voltage may cause the PFC's output voltage to change frequently, which is unfavorable for regulating voltages at subsequent stages, and the output voltage may oscillate.

The third method is the use of a variable resonant inductor [13], which engender unsaturated, partially saturated, and saturated resonant inductance values according to various loads and operating points. In addition to the difficulty in controlling the saturation point, this method is unfavorable for realizing com-

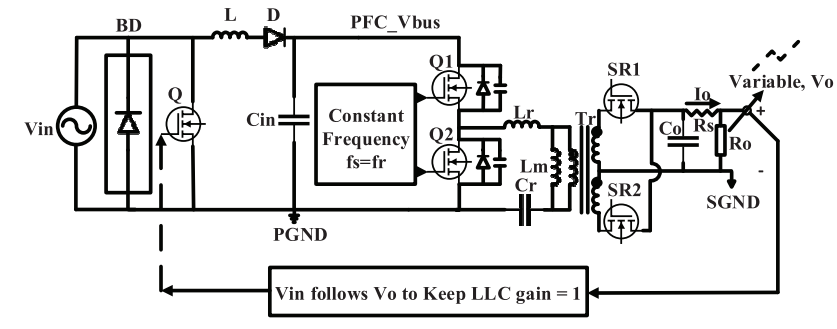

Fig. 2. Block diagram of the first method.

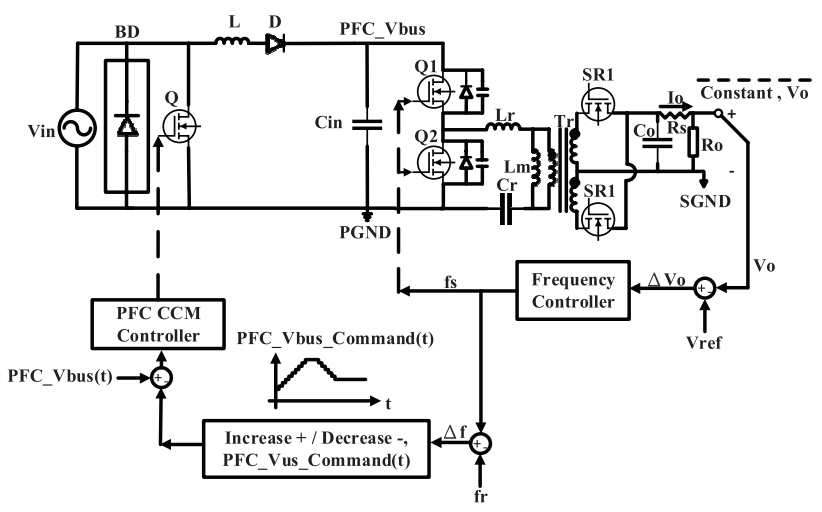

Fig. 3. Block diagram of the second method.

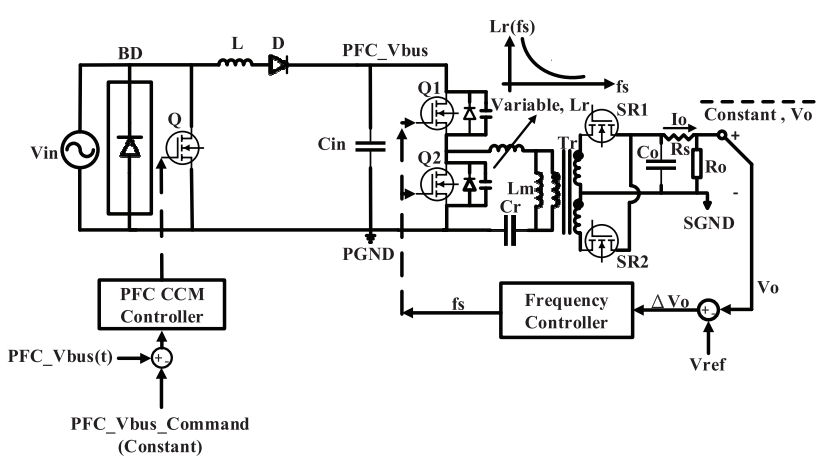

Fig. 4. Block diagram of the third method.

mercialization of mass production. The block diagram regarding the function of this architecture is shown in Fig. 4.

This study proposed a novel method for improving efficiency that does not require changes in system architecture and resonant tank components. The proposed method simply utilizes the LLC resonant converter's voltage gain and the switching frequency's open loop relationship under various loads to rapidly estimate the required input voltage compensation, enabling the switching frequency to stay consistent with the resonant frequency. When the load varies, the variable frequency control of the conventional LLC resonant converter changes the switching frequency to alter the voltage gain to compensate for the drop (rise) in the output voltage caused by the increase (decrease) of the load. If the input voltage can be altered while the load changes, voltage gain can thus be changed to achieve optimal operational efficiency under the premise of little variation in the switching frequency. The proposed method is presented in Fig. 5. Because the proposed method does not require a step-by-step 


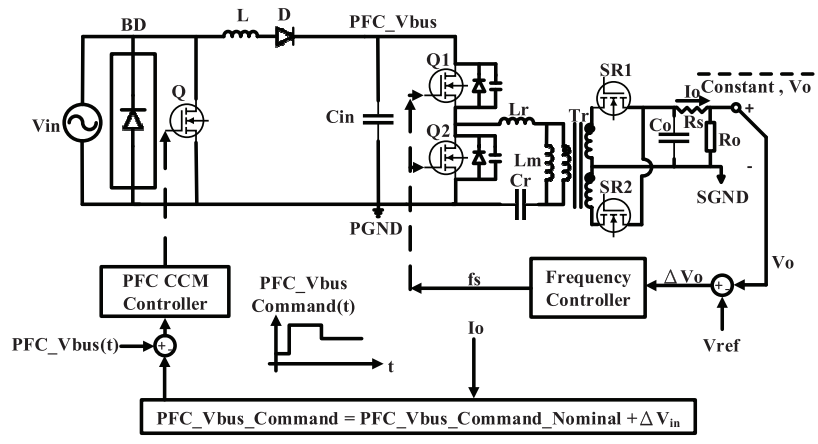

Fig. 5. Block diagram of the proposed method.

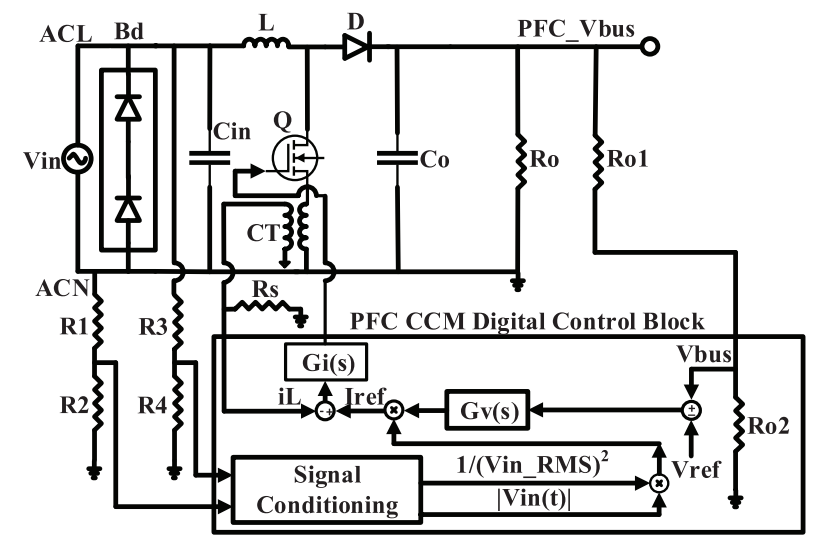

Fig. 6 Block diagrams of the PFC stage utilized in this study.

adjustment mechanism, the output response is relatively rapid. Compared with the variable frequency control of a conventional LLC resonant converter, the proposed technology can increase efficiency by $0.8 \%$ at full load.

This paper is organized as follows. Section II describes the relationship between the conversion efficiency and the output voltage of PFC. Section III presents the loss analysis of LLC resonant converter operating at the resonant frequency. Section IV derives the proposed control technique. Section $V$ reports the experimental results. Section VI draws some conclusions.

\section{The Relationship Between the Efficiency and Output Voltage of the PFC Stage}

In this paper, an adaptive DC-link voltage control technique is proposed to keep the switching frequency of the LLC resonant converter close to the designed resonant frequency. That is, the output voltage of the PFC stage should be adjustable. In this subsection, the relationship between the conversion efficiency and the output voltage value of the PFC stage is investigated. Fig. 6 shows the block diagram of the PFC stage used in this study.

From Fig. 6, the utilized PFC is a boost converter operated in average current mode [24], [25]. The input voltage range of the utilized $380 \mathrm{~W}$ PFC stage is from $90 \mathrm{~V}_{\mathrm{AC}}$ to $264 \mathrm{~V}_{\mathrm{AC}}$ with $\mathrm{AC}$ line frequency ranges from $47 \mathrm{~Hz}$ to $63 \mathrm{~Hz}$, the nominal output voltage is $380 \mathrm{VDC}$ (programmable), and the full load current is $0.92 \mathrm{~A}$. According to [26], the losses of the power MOSFET
TABLE I

Key Components of the Utilized PFC Stage

\begin{tabular}{ccc}
\hline \hline Key Components & Manufacturer and Parts & Specifications \\
\hline Bridge diode (Bd) & Fairchild, GBU8J & $\mathrm{V}_{\mathrm{RRM}}: 600 \mathrm{~V}, \mathrm{I}_{\mathrm{F}(\mathrm{AV})}: 8 \mathrm{~A}$ \\
MOSFET (Q) & Infineon, IPP60R199CP & $\mathrm{V}_{\mathrm{DS}}: 650 \mathrm{~V}, \mathrm{R}_{\mathrm{DS}(\text { (on })}: 0.199 \Omega$, \\
$\mathrm{I}_{\mathrm{D}}: 9 \mathrm{~A}$ \\
$\begin{array}{c}\text { Freewheeling } \\
\text { diode (D) }\end{array}$ & Cree, C3D10060G & $\mathrm{V}_{\mathrm{RRM}}: 600 \mathrm{~V}, \mathrm{I}_{\mathrm{F}}: 10 \mathrm{~A}$ \\
$\begin{array}{c}\text { Output Capacitor } \\
(\text { Co })\end{array}$ & Panasonic, & $450 \mathrm{~V} / 220 \mu \mathrm{F}$ \\
Controller & TI, UCD3138 & Integrated Digital Controller \\
\hline \hline
\end{tabular}

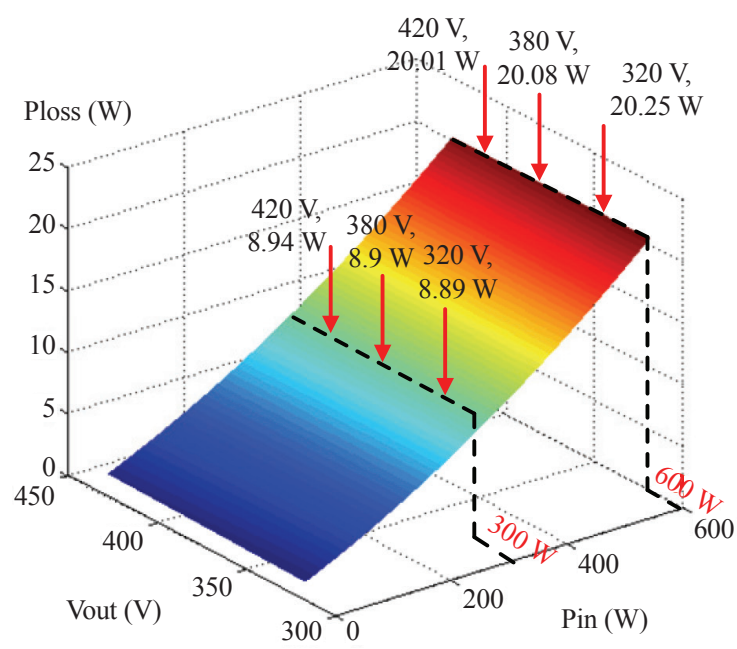

Fig. 7. Total losses of the PFC stage utilized in this study.

$\mathrm{Q}$, freewheeling diode $\mathrm{D}$, and output capacitor $\mathrm{C}_{\mathrm{o}}$ relate to the value of the output voltage $V_{o}$. TABLE I shows the key components of the implemented PFC stage. Using the parameters in TABLE I, total losses of the PFC stage can be obtained [26].

Fig. 7 shows the calculated total losses of the PFC stage under different output voltage $V_{o}$ and power level $P_{i n}$. From Fig. 7, the power losses become larger/smaller when $V_{o}$ increases under $300 \mathrm{~W} / 600 \mathrm{~W}$ power level. Nonetheless, it can also be observed from Fig. 7 that the variation of power losses for the full voltage swing $\left(V_{o}=320 \mathrm{~V}\right.$ to $\left.V_{o}=420 \mathrm{~V}\right)$ is rather small $(0.045 \mathrm{~W}(0.015$ $\%)$ for $300 \mathrm{~W}$ level and $-0.25 \mathrm{~W}(0.042 \%)$ for $600 \mathrm{~W}$ level). Therefore, changing the output voltage of PFC will have little effect on the overall efficiency.

\section{Optimal Operating Point and Loss Analysis of LLC Resonant CONVERTER}

\section{A. Comparison of Three Operating Points of the LLC Reso- nant Converter}

The key waveforms of the resonant current of LLC converter operating at different switching frequencies are depicted in Fig. 8 . If the switching frequency is lower than the resonant frequency as shown in Fig. 8(a), a large circulating current exists in the 


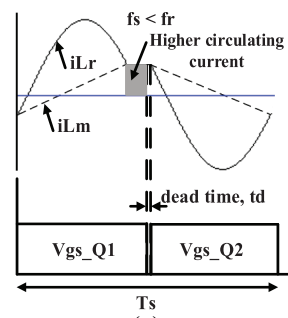

(a)

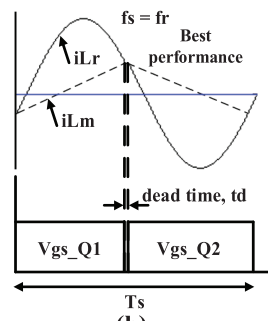

(b)

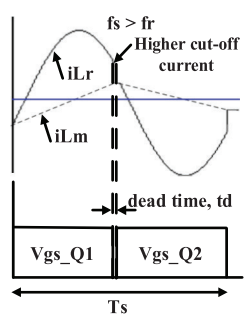

(c)
Fig. 8. Key waveforms of the resonant current $\mathrm{i}_{\mathrm{Lr}}$ of LLC resonant converter operating under different switching frequency.

TABLE II

Comparison of the LlC Resonant Converter Operating Under Different SWITCHING FREQUENCY

\begin{tabular}{lccc}
\hline \hline \multicolumn{1}{c}{ LLC Performances } & fs $<\mathrm{fr}$ & $\mathrm{fs}=\mathrm{fr}$ & $\mathrm{fs}>\mathrm{fr}$ \\
\hline Turn on loss of primary MOSFET & ZVS & ZVS & ZVS \\
Turn off loss of primary MOSFET & Low & Low & High \\
Circulating current in the primary side & High & Low & Medium \\
Secondary diode & ZCS & ZCS & No \\
Conduction loss & High & Low & Medium \\
Switching loss & Low & Low & High \\
Harmonics & Low & Low & High \\
Overall performance & Medium & Best & Medium \\
\hline \hline
\end{tabular}

resonant tank, and it will cause high conduction loss. When the switching frequency equals the resonant frequency, the switching loss and conduction loss are reduced as seen in Fig. 8(b). When the switching frequency is higher than the resonant frequency, the MOSFETs are turned off with higher current as shown in Fig. 8(c); hence, the switching loss increases. TABLE II shows the comparison of the LLC resonant converter operating under different switching frequency [14]. From TABLE II, the LLC resonant converter achieves its best efficiency when operating at the resonant frequency.

\section{B. Loss Analysis for LLC Resonant Converter Operating at the Resonant Frequency}

For the proposed control technique, the DC-link voltage will be adjusted to keep the switching frequency of LLC resonant converter near its resonant frequency. Therefore, loss analysis for LLC resonant converter operating at its resonant frequency will be performed first. For the LLC resonant converter utilized in this study, as shown in Fig. 9, the loss model for each component will be briefly derived and described as follows:

\section{1) Losses of MOSFET $Q 1$ and $Q 2$}

Conduction loss of MOSFET Q1 and Q2 can be expressed as [15]:

$P_{L L C-c o n d}=I_{p-r m s}^{2} \cdot R_{D S_{-} o n}=\left(\frac{2 P_{o}}{V_{o}} \sqrt{\frac{R_{L}^{2} T_{s}^{2}}{32 n^{4} L_{m}^{2}}+\frac{\pi^{2}}{8}}\right)^{2} \cdot R_{D S_{-} o n}$

where $I_{p_{-} \text {rms }}$ is the RMS current of the primary side, transformer

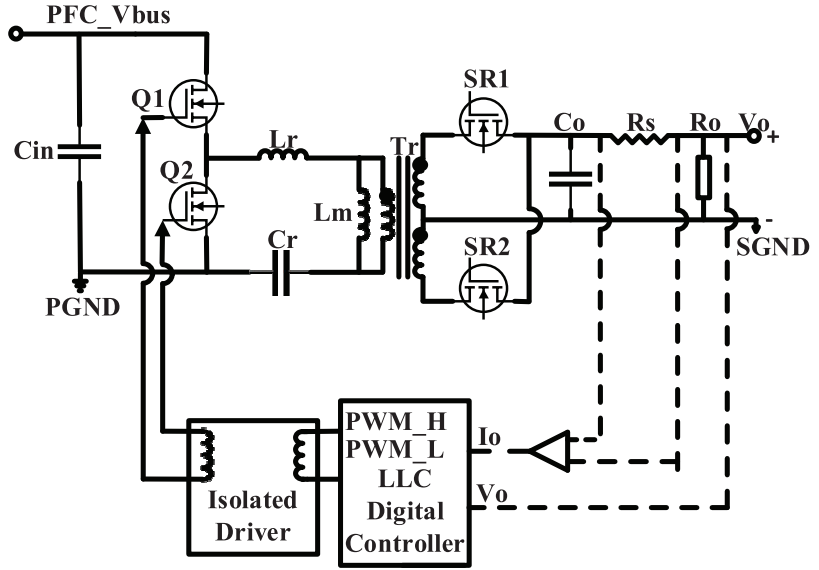

Fig. 9. LLC resonant converter utilized in this study.

turns ratio $n=N_{p} / N_{s}, N_{p}$ is the number of turns on the primary side, $N_{s}$ is the number of turns on the secondary side, $L_{m}$ is the magnetizing inductance, $V_{o}$ is the output voltage, $R_{L}$ is the equivalent load resistance and $T_{s}$ is the switching period.

Due to its ZVS nature, the turn-on loss of Q1 and Q2 can be neglected. However, there still exists a turn-off loss. The turnoff loss of MOSFETs can be depicted as [14]

$$
P_{L L C-s w_{-} \text {off }}=2\left(\frac{I_{\text {peak }}^{2} t_{f}^{2} f_{s}}{48 C_{o s s}}\right)=\frac{I_{\text {peak }}^{2} t_{f}^{2} f_{s}}{24 C_{\text {oss }}}
$$

where $I_{\text {peak }}$ is the peak value of the magnetizing current, $t_{f}$ is the rise time of the MOSFET, $f_{s}$ is the switching frequency, COSS is the output capacitance of MOSFET.

\section{2) Losses of the Isolation Transformer}

According to [31], the AC-to-DC resistance ratio $F_{R_{-} n-T r}$ can be calculated by Dowell's equation, as shown in (3)

$$
\begin{aligned}
& F_{R_{-} n_{-} T r}=\frac{R_{a c_{-} T r}}{R_{d c_{-} T r}} \\
& =\mathrm{X}_{n} \frac{\sinh 2 \mathrm{X}_{n}+\sin 2 \mathrm{X}_{n}}{\cosh 2 \mathrm{X}_{n}-\cos 2 \mathrm{X}_{n}}+2 \mathrm{X}_{n} \frac{m^{2}-1}{3} \frac{\sinh \mathrm{X}_{n}-\sin \mathrm{X}_{n}}{\cosh \mathrm{X}_{n}-\cos \mathrm{X}_{n}}
\end{aligned}
$$

where $F_{R n \text { Tr }}$ is the AC-to-DC resistance ratio at $n t h$ harmonic frequency, $R_{a c T r}$ and $R_{d c T r}$ are the $\mathrm{AC}$ and DC resistance of the transformer, respectively. $X_{n}=h / \delta_{n}$ is the ratio of wire thickness $h$ and the skin depth of $n t h$ harmonic current, $m$ is the layer number.

Hence, the AC copper loss of primary and secondary side can be obtained by summing the losses from DC to $n t h$ harmonics.

$$
\begin{gathered}
P_{\mathrm{Copper}_{-} p r i}=\sum_{n=0}^{n} F_{R_{-} n_{-} p r i} R_{d c} \cdot I_{R M S_{-} p r i}^{2} \\
P_{\text {Copper_sec }^{2}}=\sum_{n=0}^{n} F_{R_{-} n_{-} s e c} \cdot R_{d c} \cdot I_{R S_{-} s e c}^{2}
\end{gathered}
$$

From (4) and (5), the total copper loss of the transformer can be derived as: 


$$
P_{\text {Copper_} T_{r}}=P_{\text {Copper_pri }}+P_{\text {Copper_sec }}
$$

The core loss of the transformer can be calculated using the empirical Steinmetz equation [27], [28], as shown in (7):

$$
P_{\text {Core }}=K_{\text {core }} \cdot f^{\alpha} \cdot \Delta B_{T r}^{\beta} \cdot V_{e}
$$

where $K_{\text {core }}$ is the Steinmetz coefficient of the core, $V_{e}$ is the volume of the core and $\Delta B_{T r}$ is the flux swing of the transformer and can be calculated as:

$$
\Delta B_{T r}=\frac{V_{L M} \cdot D \cdot T_{s}}{N_{p} \cdot A_{e}}=\frac{n V_{o} \cdot T_{s}}{4 \cdot N_{p} \cdot A_{e}}
$$

where $V_{L M}$ is the voltage of magnetizing inductance, $D$ is the duty ratio, $T_{s}$ is the switching period, $A_{e}$ is the effective cross-sectional area of the core.

\section{3) Losses of the Resonant Inductor}

The losses in the resonant inductor include copper loss and core loss, and can be obtained as [14], [31]:

$$
P_{\text {Copper_Lr }}=\sum_{n=0}^{n} F_{R_{-} n_{-} L r} \cdot R_{d c_{-} L r} \cdot I_{L r}{ }^{2}
$$

where the AC-to-DC resistance ratio $F_{R_{-} n L r}=R_{a c \_L r} / R_{d c \_L r}, R_{a c \_L r}$ and $R_{d c L r}$ are the $\mathrm{AC}$ and $\mathrm{DC}$ resistance of the resonant inductor, respectively. $I_{L r}$ is the RMS value of the resonant inductor current.

Similarly, the core loss of the resonant inductor can be obtained using the empirical Steinmetz equation [14], [27], [28], as depicted in (10)

$$
P_{\text {Core_L } L r}=K_{\text {core } \_ \text {Lr }} \cdot f^{\alpha} \cdot \Delta B_{L r}^{\beta} \cdot V_{e_{-} L r}
$$

where $K_{\text {core } L r}$ is the Steinmetz coefficient of the resonant inductor, $V_{e L r}$ is volumn of the resonant inductor, and $\Delta B_{L r}$ is the flux swing of the resonant inductor, as shown in (11)

$$
\Delta B_{L r}=\frac{L_{r}}{n_{L r} A_{e_{-} L r}} \sqrt{\left(\frac{n V_{o} T}{4 L_{m}}\right)^{2}+\left(\frac{\pi V_{o} I_{o}}{2 V_{d c}}\right)^{2}}
$$

where $n_{L r}$ is the number of turns on the resonant inductor, $A_{e_{L L r}}$ is the effective cross-sectional area of the resonant inductor and $V_{d c}$ is the input voltage of the LLC converter.

\section{4) Losses of the Synchronous Rectifier (SR) S1 and S2}

The conduction loss of synchronous rectifier can be calculated as:

$$
P_{L L C_{-} S R_{-} \text {cond }}=I_{s_{-} r m s}{ }^{2} \cdot R_{D S \_o n}
$$

where $I_{s_{-} \text {rms }}$ can be expressed as [35]

$$
I_{s_{-} r m s}=\frac{\sqrt{3}}{24 \pi} \frac{V_{o}}{R_{L}} \sqrt{\frac{\left(5 \pi^{2}-48\right) n^{4} R_{L}^{2} T_{s}^{2}}{L_{m}^{2}}+12 \pi^{2}}
$$

When operating at its resonant frequency, the SR of LLC resonant converter exhibits ZCS; hence, the switching loss of SR is neglected.

\section{5) Total Losses of the LLC Resonant Converter}

Based on the above derivation, the total losses of the LLC resonant converter can be obtained by summing up the losses of each component shown in Fig. 9.

\section{Operating Principle of the Proposed Method}

In this paper, a novel adaptive DC-link control technique is proposed. With this approach, the LLC resonant converter will automatically adjust its input voltage to keep the switching frequency of the LLC resonant converter close to the resonant frequency so that the conversion efficiency of the LLC resonant converter can be optimized across the whole load range. According to the First Harmonic Approximation (FHA) technique, the voltage gain of the LLC resonant converter can be expressed as:

$$
\begin{aligned}
M\left(f_{n}\right) & =\frac{V_{o}}{V_{\text {in }} /(2 \cdot n)} \\
& =\left|\frac{L_{n} \cdot f_{n}^{2}}{\left[\left(L_{n}+1\right) \cdot f_{n}^{2}-1\right]+j\left[\left(f_{n}^{2}-1\right) \cdot f_{n} \cdot Q_{e} \cdot L_{n}\right]}\right|
\end{aligned}
$$

where $L_{n}=L_{m} / L_{r}$ is the ratio of the magnetizing inductance and resonant inductance, $f_{n}=f_{s} f_{r}$ is the ratio of switching frequency and resonant frequency. In (14), the quality factor $\mathrm{Q}_{\mathrm{e}}$ can be depicted as

$$
Q_{e}=\frac{\sqrt{L_{r} / C_{r}}}{R_{e}}
$$

where the equivalent load resistance $R_{e}$ can be obtained as

$$
R_{e}=\frac{8 \cdot n^{2}}{\pi^{2}} R_{o}=\frac{8 \cdot n^{2}}{\pi^{2}} \frac{V_{o}}{I_{o}}
$$

Fig. 10 shows the voltage gain curves of different values of load current. From Fig. 10, the voltage gain is irrelevant to the load current if the switching frequency is fixed at the resonant frequency. However, if non-idealities such as losses in power switches, magnetics, and diodes are taken into account, the actual output voltage will vary according to the load current [36]. When load increases/decreases, the output voltage will drop/ rise accordingly. Hence, a closed-loop controller is typically required to adjust the switching frequency to compensate the voltage variation. That is, to compensate for the effect of the varied load value, a conventional LLC resonant converter operates under a wide switching frequency variation range. However, wide frequency variation complicates the design of the LLC resonant converter and leads to a decrease of efficiency.

To deal with this problem, an adaptive DC-link voltage control method is proposed in this study. From (14), the output voltage under ideal condition can be expressed by: 


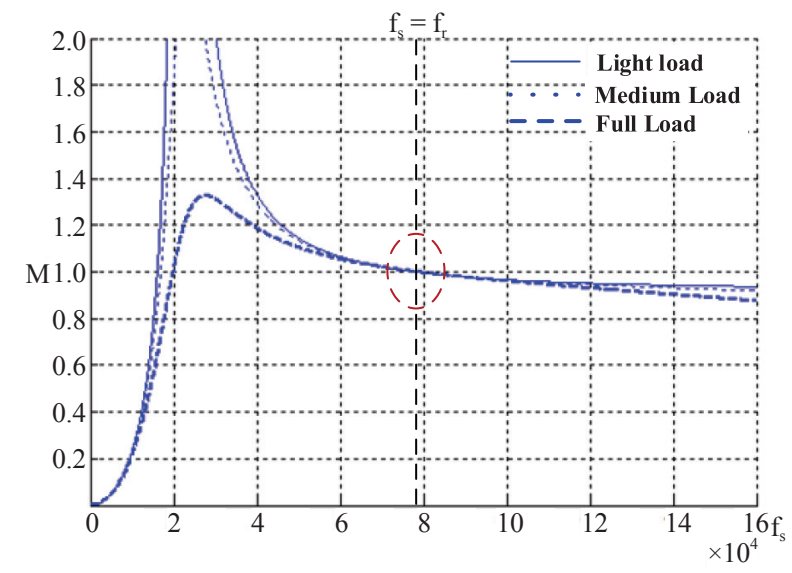

Fig. 10. Gain curves of the LLC resonant converter under different load conditions (ideal case).

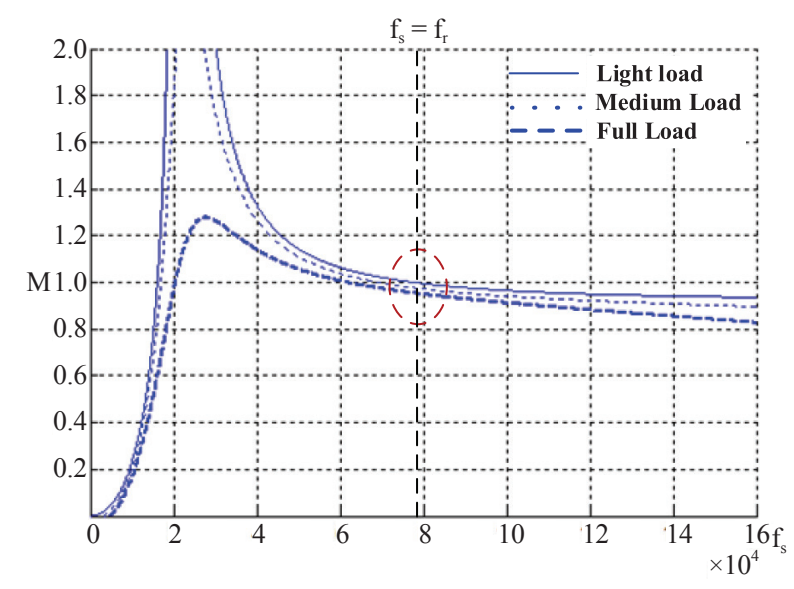

Fig. 11. Gain curves of the LLC resonant converter under different load conditions (non-ideal case).

$$
\begin{aligned}
V_{o} & =\frac{V_{i n}}{2 \cdot n} \cdot M=\frac{V_{i n}}{2 \cdot n} \cdot\left|\frac{L_{n} \cdot f_{n}^{2}}{\left[\left(L_{n}+1\right) \cdot f_{n}^{2}-1\right]+j\left[\left(f_{n}^{2}-1\right) \cdot f_{n} \cdot Q_{e} \cdot L_{n}\right]}\right| \\
& =\frac{V_{i n}}{2 \cdot n} \cdot M\left(f_{n}, Q_{e}\right)
\end{aligned}
$$

Taking all the non-idealities into consideration, the actual output voltage can be modified as:

$$
V_{o}=\frac{V_{i n}}{2 \cdot n} \cdot M\left(f_{n}, Q_{e}\right)-I_{o} \cdot R_{T}
$$

where $R_{T}$ is the equivalent resistance represents the cumulative effect of all losses and can be obtained through experiments.

Fig. 11 shows the gain curve of the utilized LLC resonant converter under different load conditions when taking all the non-idealities into account. From Fig. 11, the gain value varies even when the operating frequency is fixed at the resonant frequency. Therefore, some control technique should be employed to compensate for this gain variation.

Fig. 12 shows the changes of the gain curves of the LLC resonant converter to explain the concept of the proposed control.

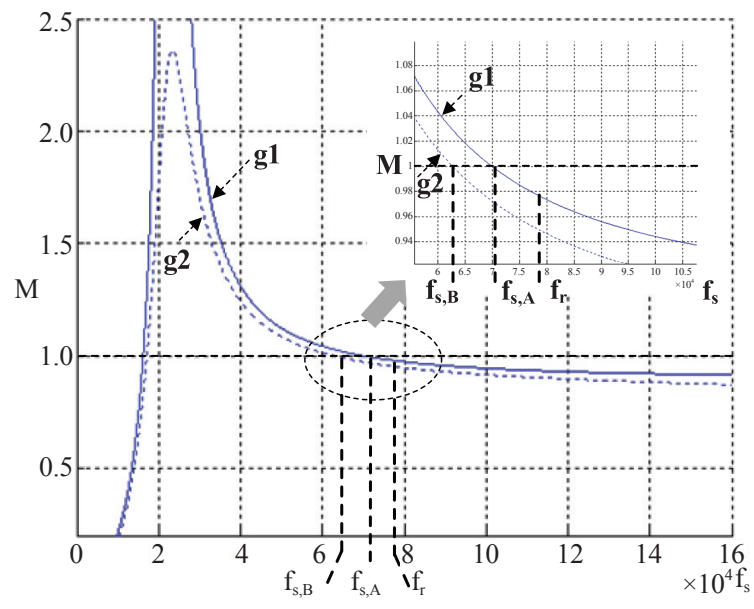

(a)

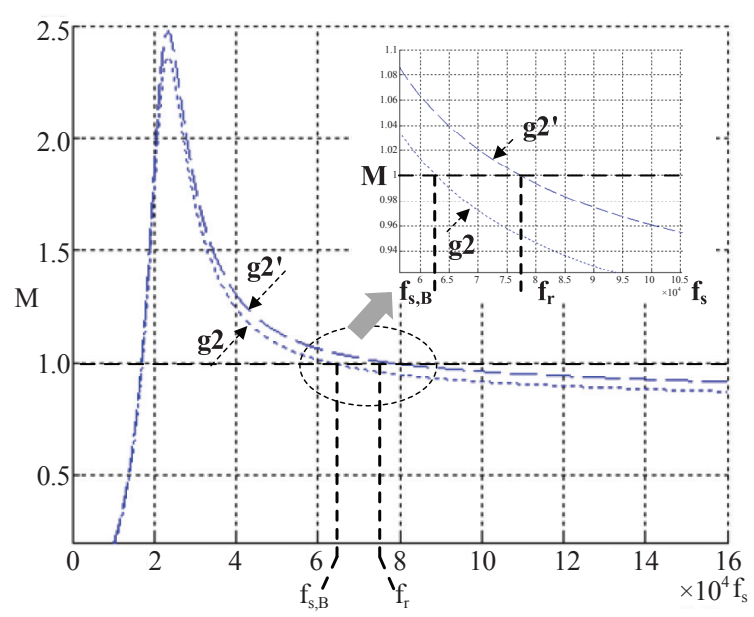

(b)

Fig. 12. Changes of gain curve under load variation in conventional and proposed control methods.

In conventional frequency control, when the load current varies from light load to heavy load condition, the gain curve changes from g1 (solid line) to g2 (dotted line). To maintain the output voltage, the controller adjusts the switching frequency of the main switches Q1 and Q2 from $f_{s, A}$ to $f_{s, B}$ to regulate the output voltage, as shown in Fig. 12 (a). On the other hand, when the load current changes from light load to heavy load in the proposed control, the output voltage is regulated by adjusting the input voltage (which consequently changes the gain curve) instead of the switching frequency as shown in Fig. 12 (b). That is, the gain curve changes from g2 (dotted line) to g2' (dashed line) to achieve a constant gain at the resonant frequency $f_{r}$.

The derivation of the proposed control mechanism can be explained as follows. According to (18), the output voltage variation $V_{o, \text { drop }}$ equals to the voltage drop across $R_{T}$, that is, $V_{o, \text { drop }}$ $=I_{o} * R_{T}$. To compensate for this voltage drop, the required voltage variation of input voltage $\Delta V_{\text {in }}$ can be calculated as

$$
\Delta V_{\text {in }}=\frac{2 \cdot n \cdot V_{o, d r o p}}{M\left(f_{n}, Q_{e}\right)}=\frac{2 \cdot n \cdot I_{o} \cdot R_{T}}{M\left(f_{n}, Q_{e}\right)}
$$




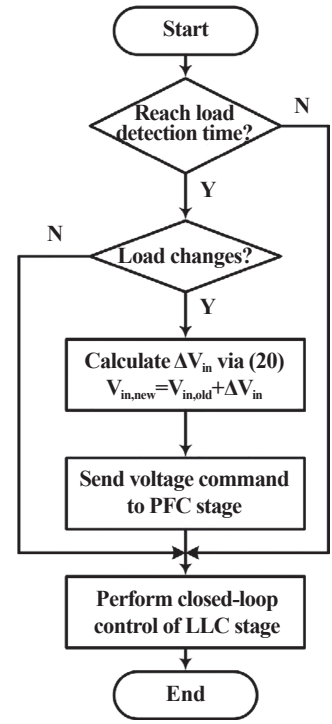

Fig. 13. Flowchart of the proposed method.

Since the gain value of the LLC resonant converter is always close to 1.0 when operating at the resonant frequency, (19) can be approximated as

$$
\Delta V_{\text {in }}=2 \cdot n \cdot I_{o} \cdot R_{T}
$$

Fig. 13 shows the flowchart of the proposed method. At first, the controller will determine whether the load detection time has been reached. In this study, the load detection time is 0.3 second. If yes, the load current value $I_{o}$ will be measured and the controller will check if the load change has occurred or not. Otherwise, only original closed-loop control will be performed. If the load level changes, the required compensation voltage can be obtained using (20). In (20), the equivalent resistance $R_{T}$ which represents the cumulative effect of all losses can be obtained by operating the LLC resonant converter at the resonant frequency using open loop control and recording voltage drop value under various load conditions. By adjusting the input voltage value and hence changing the gain curve shape, switching frequency of the resonant LLC converter can be kept around its resonant frequency. Since the adaptive DC-link voltage control scheme leads to reduced frequency variation range, optimal design of the LLC resonant converter and high efficiency under all-load conditions can be guaranteed. It should be noted that the load detection time should be slower than the bandwidth of the voltage control loop of PFC stage; otherwise the proposed method may fail to perform correctly.

The block diagram of the realized two-stage SPS with adaptive DC-link voltage control is illustrated in Fig. 14. From Fig. 14 , the only measured signals are the output voltage $V_{o}$ and output current $I_{o}$. After calculating the required input voltage variation $\Delta V_{i n}$, this command will be sent to PFC front stage via universal asynchronous receiver transmitter (UART) and the PFC stage will adjust its output voltage accordingly. Instead of continuously adjusting the input voltage as proposed in [3], the input voltage only changes once for the proposed method each

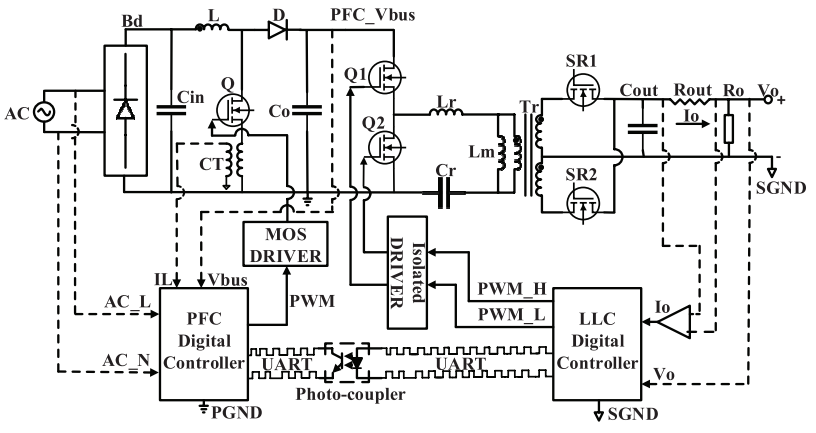

Fig. 14. Block diagram of the proposed method.

TABLE III

Components Utilized in the IMPLemented LLC Resonant Converter

\begin{tabular}{ccc}
\hline \hline Key Components & Manufacturer and Parts & Specifications \\
\hline \multirow{2}{*}{ MOSFET (Q) } & Infineon, & $\mathrm{V}_{\mathrm{DS}}: 650 \mathrm{~V}$, \\
& SPW20N60CFD & $\mathrm{R}_{\mathrm{DS}(\mathrm{on})}: 0.22 \Omega$, \\
& $\mathrm{I}_{\mathrm{D}}: 20.7 \mathrm{~A}$ \\
Synchronous Rectifier & Infineon, & $\mathrm{V}_{\mathrm{DS}}: 60 \mathrm{~V}$, \\
& IRLB3036GPbF & $\mathrm{R}_{\mathrm{DS}(\mathrm{on})}: 1.9 \mathrm{~m} \Omega$, \\
Transformer & Np:48, Ns:3, Ns:3 & $\mathrm{I}_{\mathrm{D}}: 520 \mu \mathrm{H}$ \\
Output Capacitor $(\mathrm{Co})$ & Nichicon, & 16 V/470 $\mu \mathrm{F} * 5$ \\
& PLF1C471MD01 & Integrated Digital \\
Controller & TI, UCD3138 & Controller \\
\hline \hline
\end{tabular}

time the load changes. Hence, the transient response can be improved and the output voltage oscillation phenomenon can be avoided.

\section{EXPERIMENTAL RESULTS}

In order to validate the correctness and effectiveness of the proposed method, a $350 \mathrm{~W}$ prototyping circuit is first constructed. The input voltage range of the implemented LLC resonant converter is from $350 \mathrm{~V}_{\mathrm{DC}}$ to $420 \mathrm{~V}_{\mathrm{DC}}$, the output voltage is fixed at $12 \mathrm{~V}_{\mathrm{DC}}$ and the full load current is $29 \mathrm{~A}$. Table III shows the specific components utilized in the implemented prototyping circuit and their corresponding values.

Fig. 15 displays the procedure for obtaining the equivalent resistance $R_{T}$. In Fig. 15, the realized LLC resonant converter operates at the resonant frequency using open loop control, and the load current changes from $1 \mathrm{~A}$ to full-load $29 \mathrm{~A}$ with an interval of $1 \mathrm{~A}$. After measuring the voltage variation $V_{o, d r o p}, R_{T}$ can be approximated by calculating the slope of the $V_{o, d r o p}$ versus $I_{o}$ curve. In this study, $R_{T}=37.9 \mathrm{~m} \Omega$ when load current is lower than $5 \mathrm{~A}$ and $R_{T}=15.0 \mathrm{~m} \Omega$ when load current is higher than $5 \mathrm{~A}$, as shown in Fig. 15.

Fig. 16(a) and (b) shows the key waveforms of the conventional and proposed converters in full load condition, respectively. From Fig. 16, the operating frequency of the conventional LLC resonant converter is $57.25 \mathrm{kHz}$ and the operating frequency of the proposed method is $78.64 \mathrm{kHz}$, which reduces 


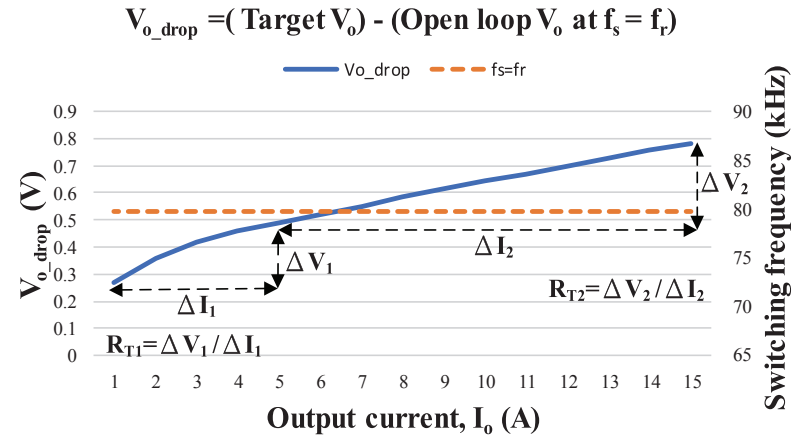

Fig. 15. Obtaining $R_{T}$ via experiments.

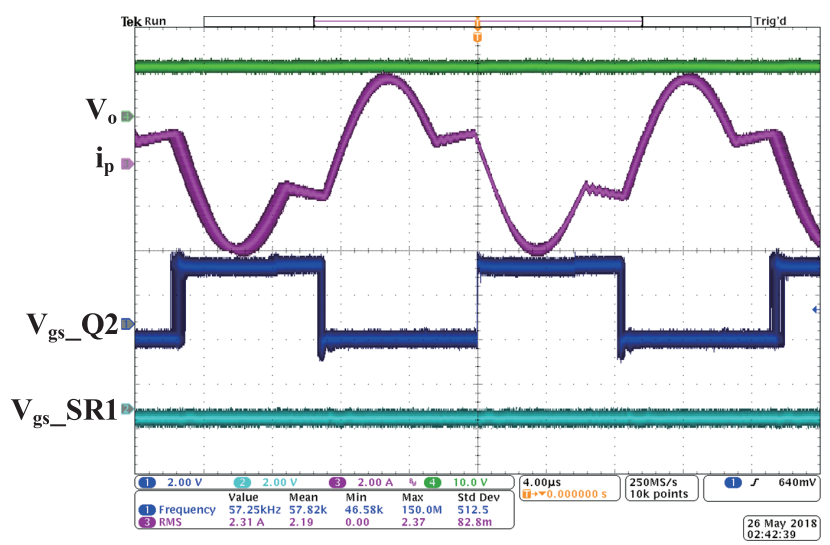

(a)

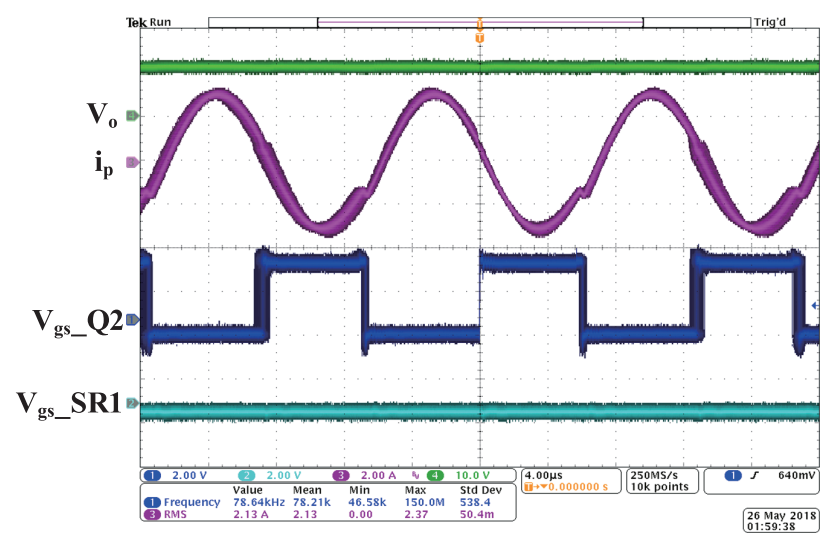

(b)

Fig. 16. Key waveforms at full load. (a) Conventional control (b) Proposed control.

the circulating loss and the switch turn-off loss in the primary side. Moreover, the proposed converter achieves ZVS over the entire load conditions. In Fig. 16(b), the input voltage changes from $380 \mathrm{~V}$ to $407 \mathrm{~V}$ to maintain the switching frequency near the resonant frequency.

Fig. 17 shows the operating frequency range and the input voltage variation of the LLC resonant converter for both the conventional and the proposed method. As shown in Fig. 17, the frequency range of the convention technique is from $85 \mathrm{kHz}$ to $73 \mathrm{kHz}$. In contrast, the frequency variation is from $76 \mathrm{kHz}$ to

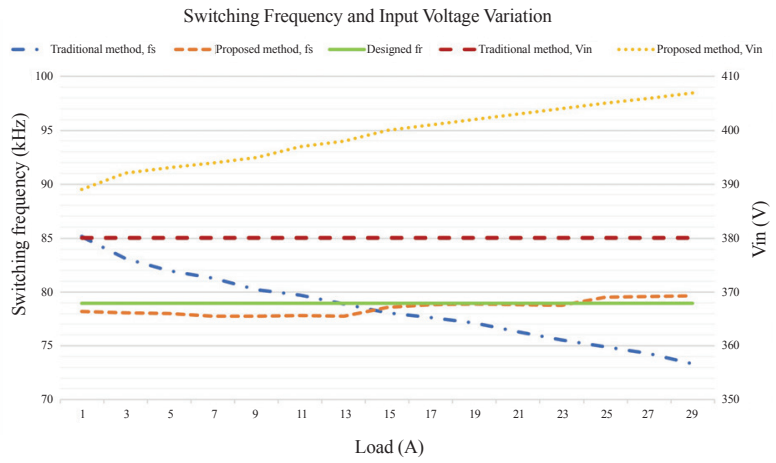

Fig. 17. Comparison of the operating frequency range and input voltage variation.

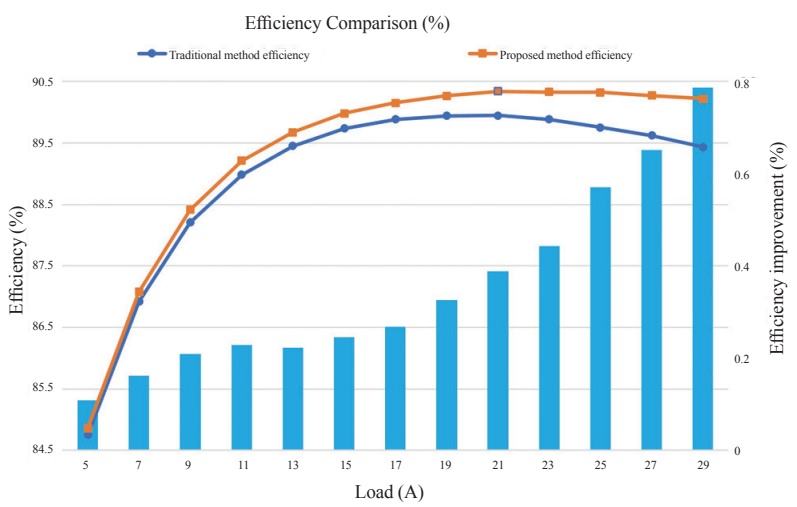

Fig. 18. Measured efficiency curves of the proposed adaptive DC-link voltage control method.

$80 \mathrm{kHz}$ for the proposed control method. It can also be observed from Fig. 17 that the input voltage of the conventional LLC resonant converter is fixed at $380 \mathrm{~V}$ while the input voltage of the proposed scheme changes from $389 \mathrm{~V}$ at light load to $407 \mathrm{~V}$ at full load. From Fig. 17, the DC-link voltage can be effectively adjusted to keep the switching frequency of LLC resonant converter near its resonant frequency.

Fig. 18 shows the measured efficiency curves of the proposed adaptive DC-link voltage control method and the conventional variable frequency control technique as load changes from $5 \mathrm{~A}$ to 29 A. From Fig 18, the proposed control technique achieves higher efficiency under all load conditions as compared to conventional LLC resonant converter, the efficiency improvement percentages are $0.13 \%, 0.27 \%$ and $0.88 \%$ under light-load, half-load and full-load conditions, and the averaged efficiency improvement is $0.427 \%$. In addition, the highest measured efficiency is $90.22 \%$.

\section{CONCLUSION}

In this study, an adaptive DC-link voltage control technique for a two-stage SPS with LLC resonant converter is proposed. With this presented technique, the DC-link voltage increases to compensate for the voltage drop caused by load variation, which facilitates the resonant LLC converter to operate near its resonant frequency. This decreases the circulating energy and makes 
the optimal design of an LLC resonant converter possible. Consequently, efficiency improvement can be achieved without any additional auxiliary circuits. According to the experimental results, the switching-frequency-variation range is reduced from $12 \mathrm{kHz}$ to $4 \mathrm{kHz}$ and the efficiency of the proposed method can be improved up to $0.13 \%, 0.27 \%$ and $0.88 \%$ under light-load, half-load, and full-load conditions, respectively.

\section{REFERENCES}

[1] M. Kasper, D. Bortis, G. Deboy, and J.W. Kolar, "Design of a highly efficient $(97.7 \%)$ and very compact $(2.2 \mathrm{~kW} / \mathrm{dm} 3)$ isolated AC-DC telecom power supply module based on the multicell ISOP converter approach," IEEE Transactions on Power Electronics, vol. 32, no. 10, pp. 7750-7769, Oct. 2017.

[2] Y. S. Lai and Z. J. Su, "New integrated control technique for twostage server power to improve efficiency under the light-load condition," IEEE Transactions on Industrial Electronics, vol. 62, no. 11, pp. 6944-6954, Nov. 2015.

[3] Z. I. Su and Y. S. Lai, "On-line DC-link voltage control of LLC resonant converter for server power applications," in IEEE ECCE Conf. Rec., Nov. 2014, pp. 5422-5428.

[4] Y. S. Lai and Z. J. Su, "Novel on-line maximum duty point tracking technique to improve two-stage server power efficiency and investigation into its impact on hold-up time," IEEE Transactions on Industrial Electronics, vol. 61, no. 5, pp. 2252-2263, May 2014

[5] J. B. Lee, J. K. Kim, J. I. Baek, J. H. Kim, and G.W. Moon, "Resonant capacitor on/off control of half-bridge LLC converter for high-efficiency server power supply," IEEE Transactions on Industrial Electronics, vol. 63, no. 9, pp. 5410-5415, Sep. 2016.

[6] G. N. B. Yadav and N. L. Narasamma, "An active soft switched phase-shifted full-bridge DC-DC converter: Analysis, modeling design, and implementation," IEEE Transactions on Power Electronics, vol. 29 , no. 9, pp. 4538-4550, Sep. 2014.

[7] I. H. Cho, K. M. Cho, J. W. Kim, and G. W. Moon, "A new phase-shifted full-bridge converter with maximum duty operation for server power system," IEEE Transactions on Power Electronics, vol. 26, no. 12, pp. 3491-3500, Dec. 2011.

[8] B. Gu, J. S. Lai, N. Kees, and C. Zheng, "Hybrid-switching fullbridge DC-DC converter with minimal voltage stress of bridge rectifier, reduced circulating losses, and filter requirement for electric vehicle battery chargers," IEEE Transactions on Power Electronics, vol. 55, no. 3, pp. 1132-1144, Mar. 2013.

[9] Y. D. Kim, K. M. Cho, D. Y. Kim, and G. W. Moon, "Wide-range ZVS phase-shift full-bridge converter with reduced conduction loss caused by circulating current," IEEE Transactions on Power Electronics, vol. 28, no. 7, pp. 3308-3316, Jul. 2013.

[10] K. B. Park, C. E. Kim, G. W. Moon, and M. J. Youn, "Voltage oscillation reduction technique for phase-shift full-bridge converter," IEEE Transactions on Industrial Electronics, vol. 54, no. 5, pp. 2779-2790, Oct. 2007.

[11] U. Kundu and P. Sensarma, "A unified approach for automatic resonant frequency tracking in LLC DC-DC converter," IEEE Transactions on Industrial Electronics, vol. 64, no. 12, pp. 9311-9321, Dec. 2017.

[12] S. K. Chung, B. G. Kang, and M. S. Kim, "Constant frequency control of LLC resonant converter using switched capacitor," IEEE Electronics Letters, vol. 49, no. 24, pp. 1556-1558, Nov. 2013.

[13] H. H. Nien, C. K. Huang, C. C. Chou, C. H. Chan, and S. K. Changchien, "Design and implementation of an LLC resonant converter with saturable resonant inductor," An International Journal of Research and Survey, ICIC Express Letters, vol. 9, no. 3, pp. 691-697, Mar. 2015.

[14] H. Wang, S. Dusmez, and A. Khaligh, "Maximum efficiency point tracking technique for LLC-based PEV chargers through variable DC link control," IEEE Transactions on Industrial Electronics, vol. 61, no. 11, pp. 6041-6049, Nov. 2014.

[15] J. Y. Lee, Y. S. Jeong, and B. M. Han, "An isolated DC/DC converter using high-frequency unregulated LLC resonant converter for fuel cell applications," IEEE Transactions on Industrial Electronics, vol. 58, no. 7, pp. 2926-2934, Jul. 2011.

[16] B. C. Kim, K. B. Park, C. E. Kim, B. H. Lee, and G. W. Moon, "LLC resonant converter with adaptive link-voltage variation for a high-power-density adapter," IEEE Transactions on Power Electronics, vol. 25, no. 9, pp. 2248-2252, Sep. 2010.

[17] J. Jang, M. Joung, B. Choi, S. Hong, and S. Lee, "Dynamic analysis and control design of optocoupler-isolated LLC series resonant converters with wide input and load variations," IET Power Electron., vol. 5, no. 6, pp. 755-764, Jan. 2012.

[18] W. Sun, Y. Xing, H. Wu, and J. Ding, "Modified high-efficiency LLC converters with two split resonant branches for wide input-voltage range applications," IEEE Transactions on Power Electronics, Early Access, 2017.

[19] H. Hu, X. Fang, F. Chen, Z. J. Shen, and I. Batarseh, “A modified high-efficiency LLC converter with two transformers for wide input-voltage range applications," IEEE Transactions on Power Electronics, vol. 28, no. 4, pp. 1946-1960, Apr. 2013.

[20] S. M. S. I. Shakib and S. Mekhilef, "A frequency adaptive phase shift modulation control based LLC series resonant converter for wide input voltage applications," IEEE Transactions on Power Electronics, vol. 32, no. 11, pp. 8360-8370, Nov. 2017.

[21] D. K. Kim, S. C. Moon, C. O. Yeon, and G. W. Moon, "High-efficiency LLC resonant converter with high voltage gain using an auxiliary LC resonant circuit," IEEE Transactions on Power Electronics, vol. 31, no. 10, pp. 6901-6909, Oct. 2016.

[22] C. Fei, Y. Yang, Q. Li, and F. C. Lee, "Shielding technique for planar matrix transformers to suppress common-mode EMI noise and improve efficiency," IEEE Transactions on Industrial Electronics, vol. 65, no. 2, pp. 1263-1272, Feb. 2018

[23] C. C. Wang, Y. C. Chang, Y. K. Lo, and H. J. Chiu, "Efficiency improvement in adjust dead-time of LLC resonant converters" IGBSG Conf. Rec., April. 2014, pp. 1-4.

[24] L. H. Dixon, "Average current mode control of switching power supplies," Unitrode Power Supply Design Seminar Manual SEM700, 1990.

[25] S. Choudhury, "Average current mode controlled power factor correction converter using TMS320LF2407A," Texas Instrument application note, 2009.

[26] S. A. Rahman, F. Stuckler, and K. Siu, "PFC boost converter design guide" Infineon application note, 2016.

[27] C. P. Steinmetz, "On the law of hysteresis," in Proc. IEEE, Feb. 1984 vol. 72, pp. 197-221.

[28] J. Reinert, A. Brockmeyer, and R. W. A. A. De Doncker, "Calculation of losses in ferro- and ferrimagnetic materials based on the modified steinmetz equation," IEEE Transactions on Industry Applications, vol. 37, no. 4, pp. 1055-1061, Jul/Aug. 2001.

[29] X. Wang, C. Jiang, B. Lei, H. Teng, H. Bai, and J. L. K. Jr, "Power-loss analysis and efficiency maximization of a silicon-carbide MOSFET-based three-phase 10-kW bidirectional EV charger using variable DC-Bus control," IEEE Transactions on Power Electronics, vol. 4, no. 3, pp. 880-892, Sep. 2016.

[30] B. Yang, F. C. Lee, A. J. Zhang, and G. Huang, "LLC resonant converter for front end dc/dc conversion," in IEEE APEC Conf. Rec., Aug. 2002, pp. 1108-1112.

[31] R. Yu, G. K. Y. Ho, B. M. H. Pong, B. W. K. Ling, and J. Lam, "Computer-aided design and optimization of high-efficiency LLC series resonant converter," IEEE Transactions on Power Electronics, vol. 27, no. 7, pp. 3243-3256, Jul. 2012.

[32] J. W. Kim, and G. W. Moon, "A new LLC series resonant converter with a narrow switching frequency variation and reduced conduction losses," IEEE Transactions on Power Electronics, vol. 29, no. 8, pp. 4278-4287, Aug. 2014.

[33] C. Shi, H. Wang, S. Dusmez, and A. Khaligh, "A SiC-based high-efficiency isolated onboard PEV charger with ultrawide DC-link voltage range," IEEE Transactions on Industrial Applications, vol. 53, no. 1, pp. 501-511, Jan./Feb. 2017

[34] Y. Jeong, G. W. Moon, and J.K. Kim, “Analysis on half-bridge LLC resonant converter by using variable inductance for high efficiency and power density server power supply," in IEEE APRC Conf. Rec., May 2017, pp. 170-177. 
[35] Y. Liu, "High efficiency optimization of LLC resonant converter for wide load range," Master's thesis, Virginia Polytechnic Institute and State University, Dec. 2007.

[36] "6th Generation CoolSiC"T, 650V SiC Schottky Diode, IDH20G65C6” Infineon datasheet, 2016.

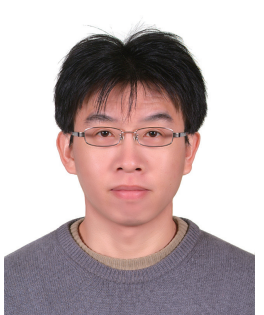

Li-Chung Shih was born in Yilan, Taiwan, R.O.C., in 1975. He received the B.S. and M.S. degree in electrical engineering at Yuan Ze University, Chung $\mathrm{Li}$, Taiwan, R.O.C. He is currently working toward the Ph.D. degree in the department of electronic and computer engineering in the Nationl Taiwan University of Science and Technology (NTUST). His research interests include power electronics, control system engineering, and digital power control.

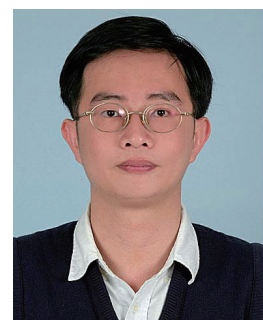

Yi-Hua Liu received the Ph.D. degree in electrical engineering from the National Taiwan University, Taipei, Taiwan, in 1998. He joined the Department of Electrical Engineering, Chang-Gung University, Taoyuan, Taiwan, in 2003. He is currently in the Department of Electrical Engineering, National Taiwan University of Science and Technology, Taipei, Taiwan. His current research interests include the areas of power electronics and battery management.

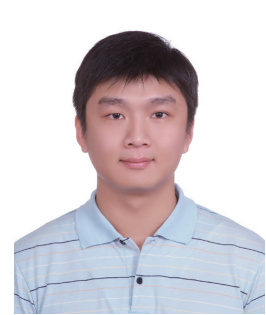

Yi-Feng Luo received the Ph.D. degree in electrical engineering from the National Taiwan University of Science and Technology, Taipei, Taiwan, in 2010. He is currently an assistant professor in the Department of Electrical Engineering, National Taiwan University of Science and Technology, Taipei, Taiwan. His current research interests include the battery management and renewable energy. 